\title{
Creating Comprehensive Children's Mental Health Indicators for British Columbia
}

\author{
Charlotte Waddell, Cody A. Shepherd, and Alice Chen \\ Simon Fraser University \\ Michael H. Boyle \\ McMaster University
}

\begin{abstract}
Canada urgently requires a population health approach to children's mental health — promoting health and preventing disorders, in addition to providing treatment. Underpinning this approach, indicators could enable population monitoring, thereby informing ongoing public investments. To investigate potential indicators for British Columbia, we developed a comprehensive population health framework, established selection guidelines, reviewed data sources, and identified sample indicators. While 15 survey and administrative sources yielded 90 indicators, there were significant imbalances in coverage of the framework. To create truly comprehensive children's mental health indicators, we therefore recommend collecting new data, enhancing existing data sources, and evaluating existing programs.
\end{abstract}

Keywords: children's mental health, population health, public policy, public data, indicators, monitoring

\section{RÉSUMÉ}

En matière de santé mentale des enfants, il est urgent que le Canada se dote d'une approche axée sur la santé de la population si nous voulons favoriser la santé et prévenir les problèmes en plus d'offrir des traitements. Cette approche devrait s'appuyer sur des indicateurs qui permettraient de faire un suivi de la santé de la population, et donc de guider les investissements publics en cours. Dans cette étude, dans le but de suggérer de tels indicateurs pour la Colombie-Britannique, nous avons conçu un cadre visant à donner une vue d'ensemble de la santé de la population, élaboré des lignes directrices pour le choix des indicateurs, évalué des sources de données et déterminé des indicateurs possibles. Nous avons ainsi retenu 15 enquêtes

Charlotte Waddell, Canada Research Chair in Children's Health Policy, Children's Health Policy Centre, Faculty of Health Sciences, Simon Fraser University. Cody A. Shepherd, Children's Health Policy Centre, Faculty of Health Sciences, Simon Fraser University. Alice Chen, Faculty of Health Sciences, Simon Fraser University. Michael H. Boyle, Canada Research Chair in Social Determinants of Child Health, Offord Centre for Child Studies, Faculty of Health Sciences, McMaster University.

We are grateful to our funders, British Columbia's Ministry of Children and Family Development and the Human Early Learning Partnership. We also thank Kimberley McEwan, Jayne Barker, Wayne Jones, and British Columbia's Child and Youth Mental Health Network for their contributions to this project.

Please address correspondence to: Charlotte Waddell, Children's Health Policy Centre, Faculty of Health Sciences, Simon Fraser University, Room 2435, 515 West Hastings Street, Vancouver, BC V6B 5K3. Tel: 778-782-7775. E-mail: charlotte_waddell@sfu.ca 
et autre sources gouvernementales de données à partir desquelles il est possible de recueillir 90 indicateurs. Toutefois, à cause des disparités entre ces sources, il est impossible de répondre intégralement aux critères de notre cadre. C'est pourquoi nous recommandons la cueillette de nouvelles données, l'amélioration des sources de données qui existent déjà et l'évaluation des programmes en place.

Mots clés : santé mentale des enfants, santé de la population, politiques publiques, données publiques, indicateurs, suivi

Mental health - or social and emotional well-being - is fundamental to human development and essential for all children to flourish. Yet at any given time, an estimated $14 \%$ of children (or 800,000 in Canada) experience mental disorders causing significant symptoms and impairment (Waddell, Offord, Shepherd, Hua, $\&$ McEwan, 2002). Exacerbating matters, clinical treatment services still reach fewer than $25 \%$ of these children despite substantial public investments in health care (Canadian Institute for Health Information, 2010; Waddell et al., 2002). Meanwhile, there are almost no investments in programs that could address determinants and prevent problems (Waddell, McEwan, Peters, Hua, \& Garland, 2007). Consequently, mental disorders unnecessarily persist throughout the lifespan, with adverse outcomes ranging from reduced educational and occupational chances to increased mortality (Boyle \& Georgiades, 2010; Fergusson, Horwood, \& Ridder, 2005; Jokela, Ferrie, \& Kivimaki, 2009). The associated economic burden is now estimated to exceed \$51 billion in Canada annually, urgently underscoring the need to better address mental health starting in childhood (Lim, Jacobs, Ohinmaa, Schopflocher, \& Dewa, 2008).

To address children's mental health adequately, a new comprehensive population health approach is needed - promoting healthy development for all children and preventing disorders in children at risk, in addition to providing effective treatment for children with established problems and disorders (Waddell, McEwan, Shepherd, Offord, \& Hua, 2005). Attending solely to any one of these promotion, prevention, or treatment components will not be sufficient to meet mental health needs, as evidenced by the current Canadian experience of investing mainly in treatment (Boyle \& Georgiades, 2010; Waddell, Shepherd, \& McLauchlin, 2008). Ongoing monitoring, underpinning a population health approach, is crucial for tracking our collective progress towards improving all children's lives (Ben-Arieh, 2008a; Junek, 2012; Moore \& Theokas, 2008; Mrazek, Biglan, \& Hawkins, 2004). Essential population health monitoring functions include identifying health needs in the population, evaluating existing public investments, and informing new investments to improve outcomes. Strategically, monitoring could also raise public awareness about the importance of children's mental health—understanding that "what gets counted, counts" —as is being done with early child development (ECD) (Hertzman \& Williams, 2009, p. 68).

Ideally for population monitoring, rigorous and repeated cross-sectional epidemiologic surveys would capture essential information on children's mental health status and determinants including trends, disparities, and access to interventions over time. Other wealthy countries conduct such surveys (Jenkins et al., 2009). However, Canada's two high-quality child mental health surveys - the 1983 Ontario Child Health Survey (OCHS) and the 1992 Quebec Child Mental Health Survey-have not been repeated, largely because of financial constraints (Boyle et al., 1987; Breton et al., 1999; Offord et al., 1987). As a result, Canada cur- 
rently lacks a coherent approach to population monitoring as a crucial platform for improving children's mental health.

In the absence of new surveys, indicators derived from existing public data sources could potentially enable population monitoring for children's mental health. An indicator is simply "a measure that summarizes information relevant to a particular phenomenon, or a reasonable proxy for such a measure" (Jenkins, 1990, p. 501). Indicators have been widely hailed as a means of spurring policy change on behalf of children (Ben-Arieh, 2008a, 2008b; Junek, 2012; Moore \& Theokas, 2008; Moore, Vandivere, Atienza, \& Thiot, 2008). There are also ample public data in Canada, collected for other purposes but potentially available for secondary analysis and indicator development (Black, McGrail, Fooks, Baranek, \& Maslove, 2005). Furthermore, Canadian policy-makers have repeatedly suggested that they would welcome children's mental health indicators (Junek, 2012).

While they are neither specific nor comprehensive regarding children's mental health, there are nevertheless several encouraging models for indicator development in Canada. The Manitoba Centre for Health Policy routinely gathers administrative data and tracks measures of children's health and development, including the prevalence of autism spectrum disorders (ASD) and attention-deficit/hyperactivity disorder (ADHD) (Brownell et al., 2008). The Human Early Learning Partnership in British Columbia and the Offord Centre for Child Studies in Ontario and other provinces use the Early Development Instrument (EDI) to regularly survey the school readiness of young children (Janus et al., 2007; Janus \& Offord, 2007; Kershaw, Anderson, Warburton, \& Hertzman, 2009). There have also been previous agreements between all levels of government to monitor ECD outcomes (Government of Canada, 2007). Meanwhile, the Canadian Institute for Health Information routinely monitors children's health care indicators, primarily drawing on provincial/territorial administrative data regarding physician and hospital services (Canadian Institute for Health Information, 2010). The robustness of these efforts strongly suggests that creating children's mental health indicators should be feasible.

Given our overarching goal of advancing a population health approach to children's mental health, we aimed to explore whether comprehensive indicators could be derived from existing public data sources. Indicators are particularly germane for provinces/territories, where most health and social programs are administered. Therefore we specifically aimed to determine whether children's mental health indicators could be created to fulfill essential population monitoring functions for the province of British Columbia.

\section{APPROACH}

We began by consulting with B.C. policy-makers on the potential applications of indicators through a longstanding research-policy partnership in children's mental health (Waddell, Shepherd, \& Barker, 2007). We then developed a comprehensive conceptual framework: to capture information on all the relevant aspects of children's mental health, and to ensure that indicator development was not driven by data availability. We also established guidelines to ensure a parsimonious selection of indicators, based on policy-makers' advice that this would enhance usefulness. Following this, we reviewed available data sources to identify sample indicators that could be mapped onto the population health framework. 


\section{Population Health Framework}

A population health approach for children's mental health - promoting health and preventing disorders, in addition to providing treatment - requires a correspondingly broad framework encompassing concepts central to the social and emotional well-being of the entire population of children. Therefore we propose a comprehensive framework that covers: major developmental stages; determinants and contexts; mental health status and related developmental domains; and a wide range of intervention approaches. This framework is depicted in Figure 1.

\section{Figure 1}

Population Health Framework for Children's Mental Health Indicators

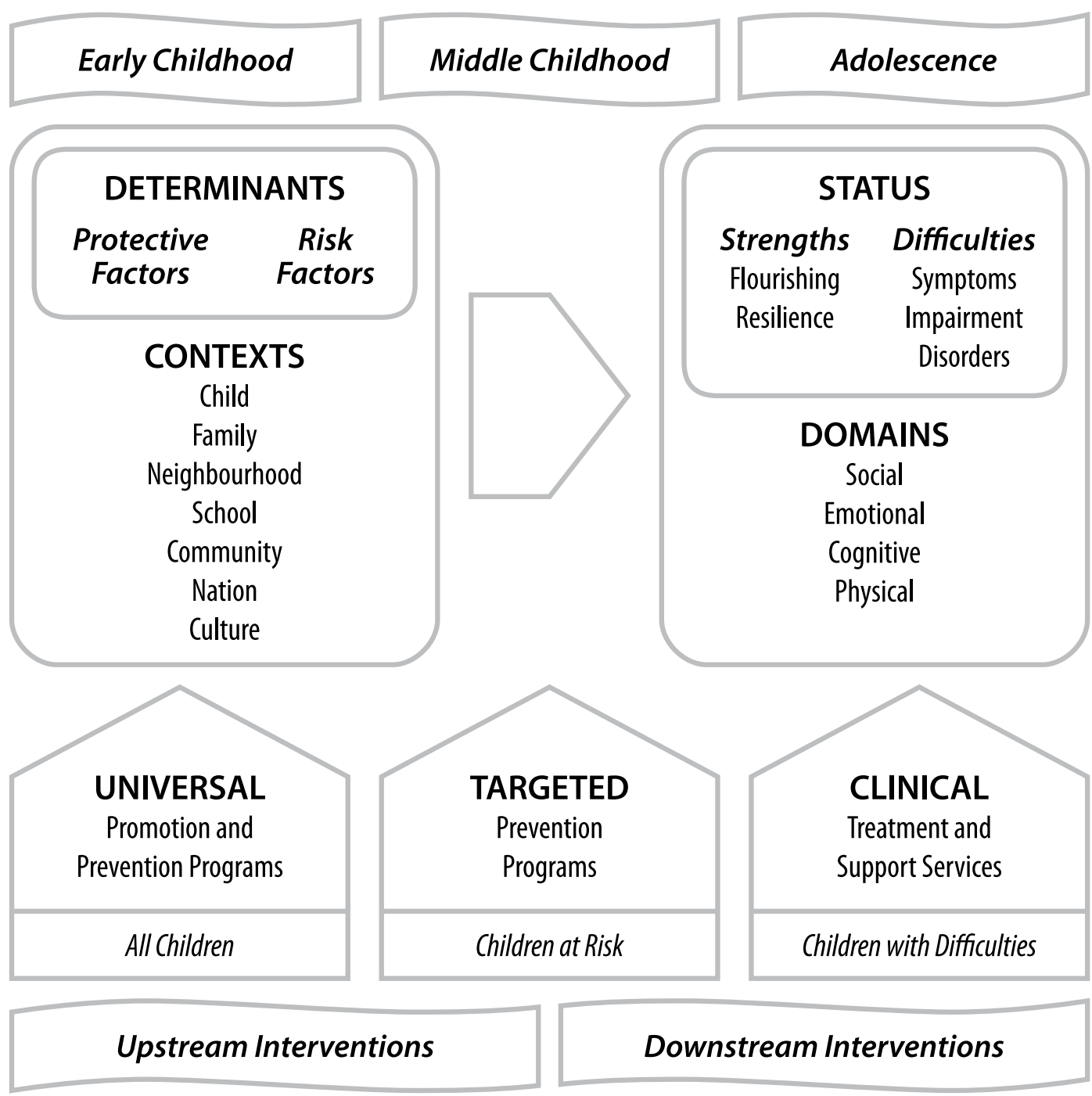


The framework first incorporates the full continuum of developmental stages-from early childhood (starting prenatally) through middle childhood and adolescence- because each constitutes a distinct period with lasting consequences. For example, certain mental disorders tend to emerge at particular stages: ASD and ADHD during early childhood; anxiety disorders during middle childhood; and depression, substance abuse, and psychotic disorders during adolescence. Limiting the framework to just one or two stages would omit important developmental implications specific to each of these disorders.

The framework next incorporates determinants of mental health and disorder. Child development constitutes a highly dynamic process, entailing multiple interactions among individual and environmental factors occurring over time (Rutter, 2009). Within this process, mental health and disorder are thought to arise from the interplay of causal protective and risk factors (Essex et al., 2006; Rutter, 2009; Shanahan, Copeland, Costello, \& Angold, 2008). While scientific evidence is still emerging on protective factors, several risk factors are now well established, including exposure to child maltreatment and to parental mental disorder (Essex et al., 2006; Shanahan et al., 2008). Protective and risk factors in turn occur within a series of contexts, from the proximal (child, family, neighbourhood, school) to the distal (community, culture, nation) (Boyle \& Lipman, 2002; Earls \& Carlson, 2001). These contexts are also captured in the framework.

Mental health status follows determinants in the framework. We propose starting with strengths - defined as flourishing, or thriving commensurate with potential, and resilience, or thriving despite adversity. Resilience has been well characterized in the developmental psychopathology literature, but there is still no consensus on defining and measuring positive concepts of children's social and emotional well-being (Moore \& Theokas, 2008; Pollard \& Lee, 2003; Rutter, 2006). Therefore we propose flourishing in supportive conditions as a counterpart to resilience in adverse circumstances. We also propose including difficulties, namely symptoms, impairment, and disorders. These constructs have been well characterized in the child psychiatric epidemiology literature, albeit with some persistent measurement challenges (Boyle \& Georgiades, 2010; Winters, Collett, \& Myers, 2005). In the framework, strengths and difficulties are then situated within developmental domains. For children's mental health, the social and emotional domains predominate, while the cognitive and physical are also recognized as integral to development.

Finally, for policy salience, the framework is grounded in the continuum of interventions - from upstream (promoting health and preventing disorders) through downstream (treating problems and minimizing their impact). Within this continuum, universal promotion and prevention programs aim to modify determinants for all children, targeted prevention programs aim to modify determinants for children at risk, and clinical treatment and support services aim to modify status for children with established difficulties (Mrazek \& Haggerty, 1994; Offord, Kraemer, Kazdin, Jensen, \& Harrington, 1998).

\section{Indicator Selection Guidelines}

A broad framework has the potential to encourage a proliferation of indicators. Therefore we developed the guidelines to ensure a relatively parsimonious selection of indicators. In particular, we suggest that indicators need to be meaningful and actionable from both policy and research perspectives. From a policy perspective, meaningful indicators are arguably those that are conceptually coherent and relevant to public policy goals (Ben-Arieh, 2008b). To be actionable, they should also reflect variables that can actually be modified through public interventions. At the same time, from a research perspective, meaningful indicators 
should ideally reflect the best available research evidence to provide some assurance that measures are reliable and valid (Jenkins, 1990). Then to be actionable from a research perspective, data should be accessible on an ongoing basis, permitting measurement and reporting at repeated intervals, thereby facilitating population monitoring over time. Figure 2 depicts proposed guidelines for indicator selection based on these principles. When in doubt, guidelines were interpreted liberally to maximize the potential indicators available for this exploratory exercise.

Figure 2

Selection Guidelines for Children's Mental Health Indicators

\begin{tabular}{|l|l|l|}
\cline { 2 - 3 } & \multicolumn{1}{|c|}{ Policy Perspective } & \multicolumn{1}{c|}{ Research Perspective } \\
\hline Meaningful & $\begin{array}{l}\text { Indicator is conceptually coherent } \\
\text { to policy-makers and relevant to } \\
\text { public policy goals }\end{array}$ & $\begin{array}{l}\text { Indicator reflects research evidence } \\
\text { on reliable and valid measures of } \\
\text { determinants and status }\end{array}$ \\
\hline Actionable & $\begin{array}{l}\text { Indicator reflects a variable that } \\
\text { can be modified through public } \\
\text { policy interventions }\end{array}$ & $\begin{array}{l}\text { Indicator is derived from accessible } \\
\text { public data that permit ongoing } \\
\text { measurement and reporting }\end{array}$ \\
\hline
\end{tabular}

\section{Data Sources and Sample Indicators}

We identified all Canada-wide and B.C.-specific survey and administrative public data sources relevant to children's mental health — by scanning websites, then approaching data stewards to confirm scope, methods, measures, and access procedures. Next, applying the selection guidelines, we selected preliminary indicators from each data source, accessed the data, and verified that each indicator could be measured (from either Canada-wide or B.C.-specific sources) over multiple time points and for all regions of the province. From this we derived a shortlist of suitable data sources and sample indicators. Finally, we mapped the sample indicators onto the various components of the population health framework to assess comprehensiveness of coverage.

\section{FINDINGS}

\section{Data Sources}

Following the approach outlined above, we identified 15 Canada-wide or B.C.-specific data sources suitable for deriving children's mental health indicators. These include 6 sources of survey and administrative data managed by Statistics Canada: Canada Census; National Longitudinal Survey of Children and Youth (NLSCY); Canadian Community Health Survey (CCHS); Uniform Crime Reporting Survey (UCRS); Youth 
Court Survey; and Corrections Key Indicator Report (CKIR). The other 9 sources of survey and administrative data are managed by a variety of B.C. stewards: Medical Services Plan (MSP); Discharge Abstract Database (DAD); Brief Child and Family Phone Interview (BCFPI); Vital Statistics; PharmaNet; Education Data; Early Development Instrument (EDI); Adolescent Health Survey (AHS); and Socio-Economic Profiles. Tables 1 and 2 describe these 15 sources.

As Tables 1 and 2 illustrate, there was considerable variation in scope and accessibility across the data sources. This is not surprising given that different sources generated data for different purposes. Regarding scope, coverage ranged from information on the entire child population to information on children receiving specialized services (e.g., youth justice, mental health, special education, child protection). All ages were represented, but middle childhood somewhat less so than early childhood and adolescence. Regarding accessibility, data were obtainable over two or more time points from each of the 15 sources. However, some had stringent access procedures resulting in significant delays (e.g., 2 or more years for MSP data), confirming previous observations that many data sources are available but few are easily accessible (Black et al., 2005). As well, some sources only made aggregate data available, while individual data are preferable for comparing data across sources and for generating specific indicators.

Data quality also varied enormously across the 15 sources. For surveys, it is crucial that the sample be representative. At one end of the spectrum, Statistics Canada used probability sampling to ensure representation of the entire population in the Census, and to represent the majority of the population in the NLSCY and CCHS (albeit excluding residents of Aboriginal reserves, military bases, and institutions). Then within B.C., Vital Statistics covered the entire population, while the EDI covered all children attending kindergarten in public, independent, or Aboriginal schools (home-schooled children were excluded). Conversely, at the other end of the spectrum, the AHS was still striving to be representative.

Then, regarding administrative data, most sources covered the entire population within their defined catchments. The one exception was the newly adopted BCFPI, with variable implementation across B.C. However, administrative catchments for most sources were narrowly defined as children receiving specialized services, with little information on the appropriateness or effectiveness of those services. Meanwhile, some surveys adopted new measures as these became available over time (e.g., NLSCY, CCHS), whereas some administrative sources retained outdated measures (e.g., diagnostic criteria used by MSP). Almost all sources relied on single informants, even though the assessment of children's symptoms and impairment is greatly improved by reports from multiple informants (Boyle et al., 1987). As well, there was little overlap across sources, and as a result it was difficult to corroborate indicators. Nevertheless the NLSCY, EDI, and BCFPI were all notable for deriving their measures from rigorous epidemiologic scales originally developed for OCHS (Cunningham, Boyle, Hong, Pettingill, \& Bohaychuk, 2009; Janus \& Offord, 2007; Willms, 2002).

\section{Sample Indicators}

Applying the selection guidelines, 90 sample indicators were derived from the 15 data sources and mapped onto the population health framework for children's mental health. Sample indicators are depicted in Tables 3 and 4, with applicable framework components noted for each. Table 5 then summarizes the indicators available for populating the major framework components (determinants, status, and interventions) across the major developmental stages. 
Table 1

Canada-Wide Data Sources for Children's Mental Health Indicators

\# Source Description

1 Canada Census Statistics Canada

2 National Longitudinal Survey of Children and Youth Statistics Canada

3 Canadian Community Health Survey Statistics Canada

4 Uniform Crime Reporting Survey Statistics Canada

$5 \quad$ Youth Court Survey Statistics Canada

- Census of the population with detailed data collected from random $20 \%$ sample (indicators derived from detailed data only)

- Data collected from parents or caregivers every 5 years since 1956, participation made voluntary as of 2011

- Representative of all children 0-18 years (and adults) in private households (excluding institutions)

- Individual data available as well as aggregate data at various contextual levels (e.g., neighbourhoods, health regions, provinces/territories)

- Survey of early child development based on Ontario Child Health Survey scales (indicators derived from cross-sectional component only)

- Data collected from parents or caregivers every 2 years since 1994, replaced by the Survey of Young Canadians as of 2010

- Representative of all children 0-5 years in private households (excluding institutions, Aboriginal reserves, military bases, and territories)

- Individual data available as well as aggregate data at various contextual levels (e.g., neighbourhoods, health regions, provinces/territories)

- Survey of adolescent (and adult) health

- Data collected from children (and adults) every 2 years from 2000 to 2007 and annually since 2007

- Representative of all children 12-18 years (and adults) in private households (excluding institutions, Aboriginal reserves, and military bases)

- Individual data available as well as aggregate data at various contextual levels (e.g., neighbourhoods, health regions, provinces/territories)

- Administrative data on all criminal incidents reported to police

- Data collected from police monthly from since 1962; more detailed incident-based data gathered since 1988

- Includes all children 0-18 years (and adults) involved in incidents reported to police

- Aggregate data available for police jurisdictions

- Administrative data on all criminal charges and convictions, under the Young Offenders' Act until 2003, Youth Criminal Justice Act since 2003

- Data collected from court staff annually since 2000

- Includes all children 12-17 years appearing in court

- Aggregate data available for provinces/territories

6 Corrections Key Indicator Report Statistics Canada
- Administrative data on all children (and adults) on probation or incarcerated

- Data collected from corrections staff monthly since 1985

- Includes all children 12-18 years (and adults) on probation or incarcerated

- Aggregate data available for provinces/territories 
Table 2

\section{B.C.-Specific Data Sources for Children's Mental Health Indicators}

\# Source Description

1 Medical Services Plan

Ministry of Health

2 Discharge Abstract Database Ministry of Health

3 Brief Child and Family Phone Interview Ministry of Children and Family Development (MCFD)

$4 \quad$ Vital Statistics Ministry of Health

5 PharmaNet Ministry of Health

6 Education Data Ministry of Education
- Administrative data on fee-for-service physician contacts and diagnoses (using International Classification of Diseases [ICD] 9th Edition)

- Data collected from physicians continuously since 1985 (excluding $\sim 10 \%$ of physicians remunerated through alternative payment programs)

- Includes all children 0-18 years (and adults) receiving fee-for-service physician services in the community or in hospitals

- Individual data available as well as aggregate data at various contextual levels (e.g., neighbourhoods, health regions, province)

- Administrative data on hospital discharges and diagnoses (using ICD 10th Edition)

- Data collected from physicians continuously since 1985

- Includes all children 0-18 years (and adults) receiving hospital services (including day procedures but excluding emergency room visits)

- Individual data available as well as aggregate data at various contextual levels (e.g., health regions, province)

- Administrative data on MCFD community mental health intake assessments based on Ontario Child Health Survey (OCHS) scales

- Data collected from children, parents, or teachers continuously since 2005

- Includes most children 6-18 years referred to MCFD community mental health services (implementation varies region to region)

- Individual data available as well as aggregate data at various contextual levels (e.g., MCFD regions, province)

- Census of all deaths (including causes) registered in British Columbia (B.C.)

- Data collected from physicians and coroners continuously since 1985

- Includes all children 0-18 years (and adults) who have died

- Individual data available as well as aggregate data at various contextual levels (e.g., health regions, province)

- Administrative data on prescriptions dispensed in the community

- Data collected from pharmacists continuously since 1996

- Includes all children 0-18 years (and adults) receiving prescriptions

- Individual data available as well as aggregate data at various contextual levels (e.g., health regions, province)

- Administrative data on student assessments (Grades 4, 7, 10-12), high school completion, and special education enrollment

- Data collected from school staff annually since 1995 (including public, independent, and Aboriginal schools)

- Includes all children 5-18 years in kindergarten through Grade 12 (excluding $\sim 10 \%$ of students who do not complete assessments)

- Individual data available as well as aggregate data at various contextual levels (e.g., schools, school districts, province) 
Table 2

(continued)

\begin{tabular}{|c|c|c|}
\hline \# & Source & Description \\
\hline 7 & $\begin{array}{l}\text { Early Development } \\
\text { Instrument } \\
\text { Human Early Learning } \\
\text { Partnership }\end{array}$ & $\begin{array}{l}\text { - Survey of early child development based on OCHS scales } \\
\text { - Data collected from teachers every } 3 \text { years in most schools since 2001, annually in } \\
\text { all schools since } 2009 \\
\text { - Includes all children 5-6 years enrolled in kindergarten (including public, indepen- } \\
\text { dent, and Aboriginal schools) } \\
\text { - Individual data available as well as aggregate data at various contextual levels } \\
\text { (e.g., neighbourhoods, health regions, province) }\end{array}$ \\
\hline 8 & $\begin{array}{l}\text { Adolescent Health } \\
\text { Survey } \\
\text { McCreary Centre } \\
\text { Society }\end{array}$ & $\begin{array}{l}\text { - Survey of adolescent development } \\
\text { - Data collected from children every } 5 \text { years in most high schools since } 1992 \text { (2008 } \\
\text { survey reached } \sim 90 \% \text { of students) } \\
\text { - Includes most children } 12-18 \text { years in Grades } 7-12 \text { (excluding independent and } \\
\text { Aboriginal schools) } \\
\text { - Individual data available as well as aggregate data at various contextual levels } \\
\text { (e.g., health regions, province) }\end{array}$ \\
\hline 9 & $\begin{array}{l}\text { Socio-Economic } \\
\text { Profiles } \\
\text { BC Stats }\end{array}$ & $\begin{array}{l}\text { - Community profiles compiled from Canada Census and various B.C. government } \\
\text { data sources (indicators derived from B.C. sources only) } \\
\text { - Data compiled annually } \\
\text { - Includes all children } 0-18 \text { years (and adults) living in B.C. } \\
\text { - Aggregate data available for school districts and local health areas }\end{array}$ \\
\hline
\end{tabular}

As Tables 3 and 4 demonstrate, existing public data could be used to generate an array of indicators relevant to children's mental health. Regarding Canada-wide sources, the large Statistics Canada surveys (the Census, NLSCY, and CCHS) yielded 36 indicators of determinants (mainly risk factors such as low family socio-economic status or unsafe neighbourhoods) and status (mainly difficulties such as symptoms of mental disorders). Meanwhile youth justice administrative data yielded 8 indicators of determinants, status, and downstream interventions. Many indicators of determinants depicted the family context, reflecting the focus of data collection. Notably, however, data from the Census, NLSCY, and CCHS may be aggregated to multiple levels of measurement, thereby permitting comparisons across other contexts of interest for population health monitoring, such as neighbourhoods.

Turning to the B.C.-specific sources, administrative data yielded 35 indicators almost exclusively depicting status (mainly difficulties such as symptoms or diagnoses of mental disorders) or downstream interventions. Meanwhile, the EDI, AHS, and Vital Statistics surveys yielded 11 indicators of status (namely development in kindergarten and high school, as well as child deaths). The EDI and Education Data were most notable for capturing strengths - healthy development in kindergarten, subsequent academic achievement, and high-school completion. Indicators of determinants from B.C.-specific sources typically depicted the family and school contexts, but many of these data could also be aggregated to multiple contextual levels. 


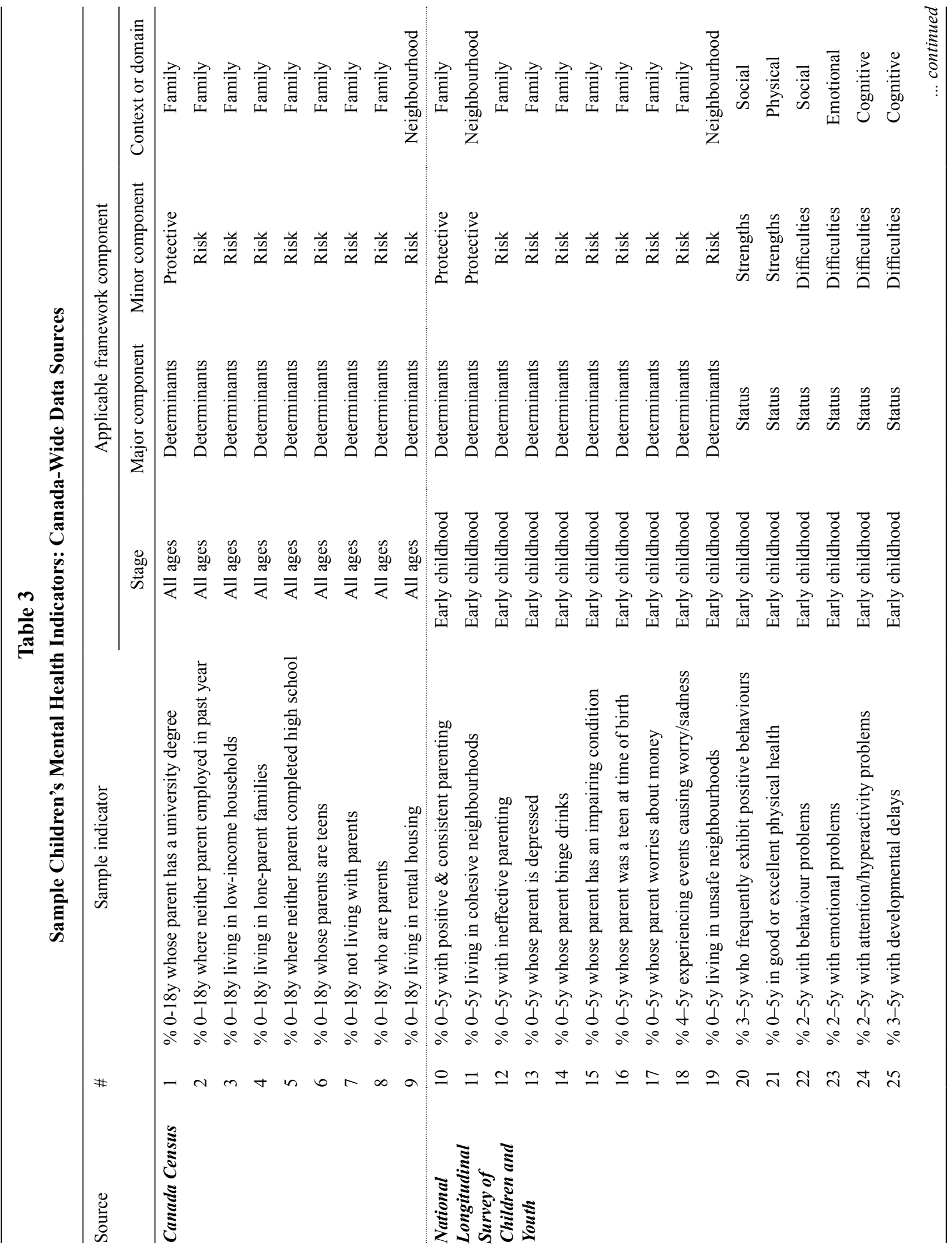




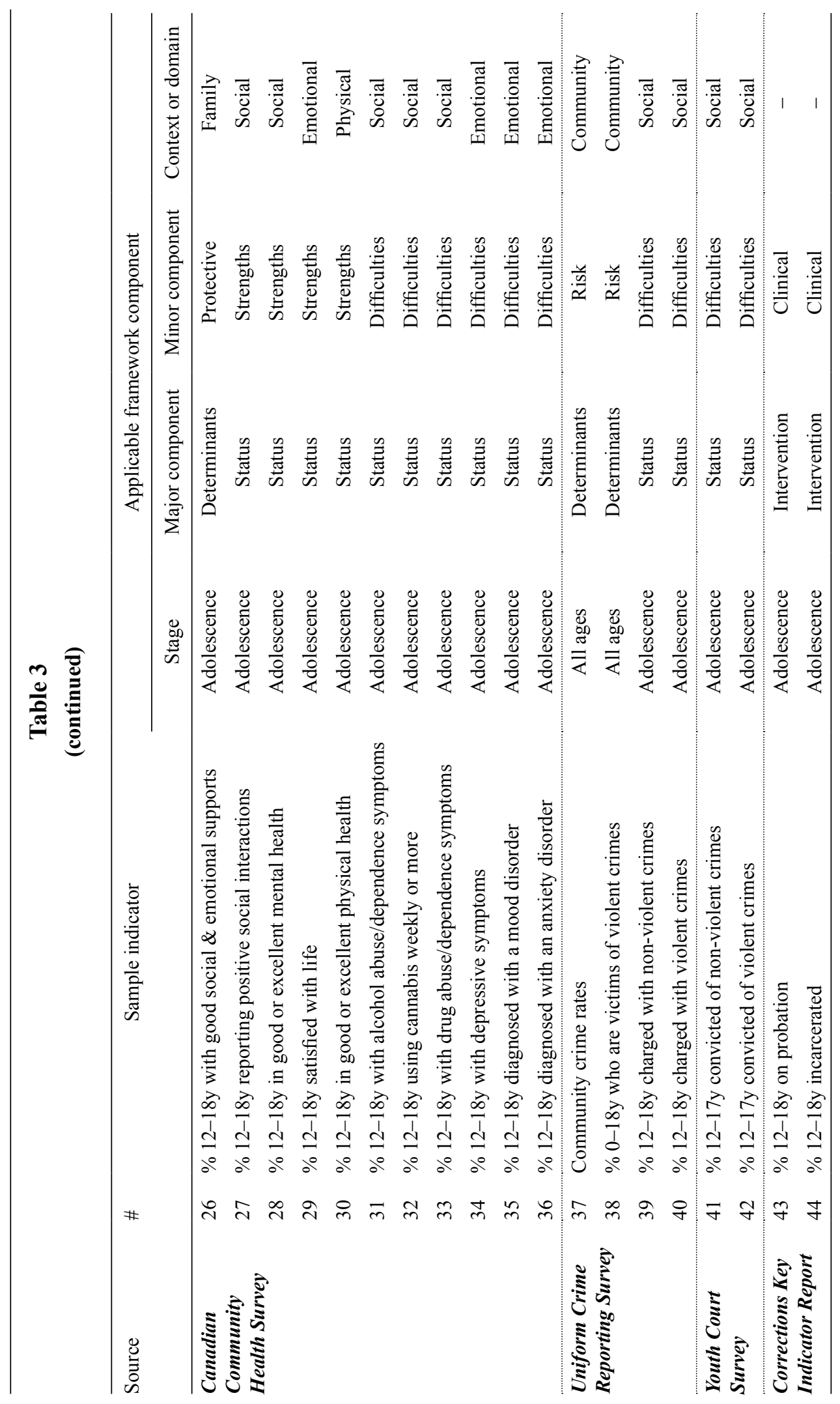




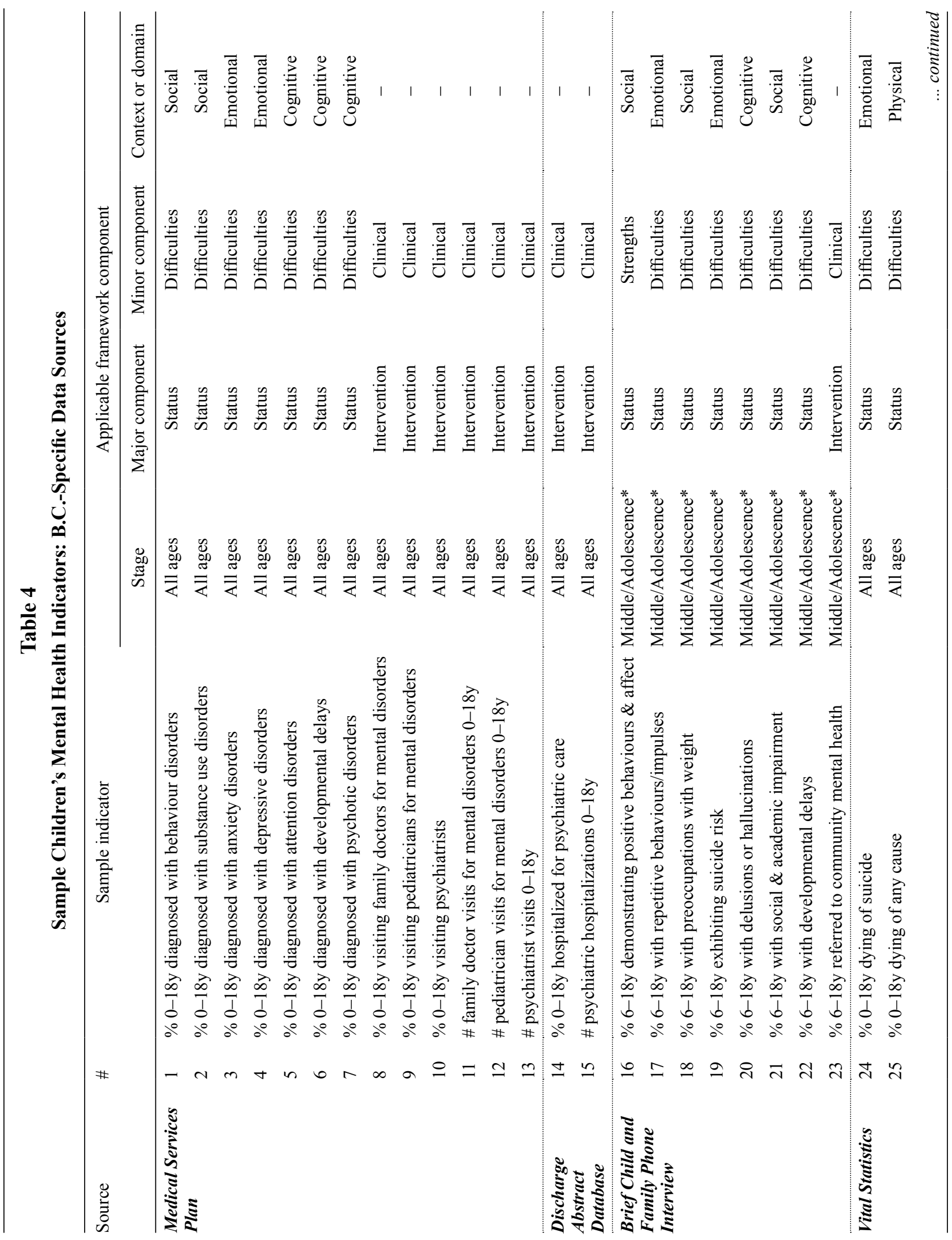




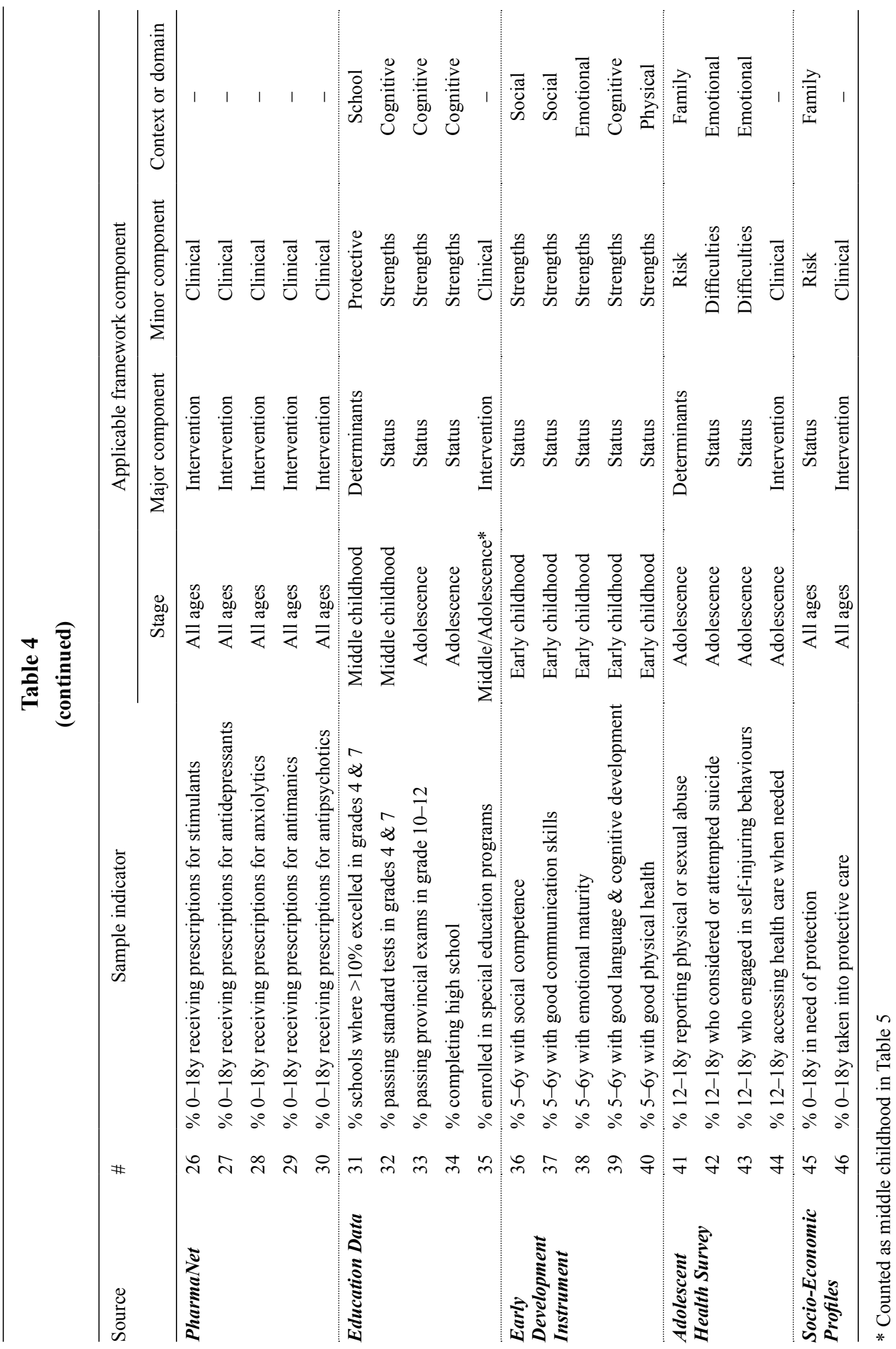


Table 5

Sample Children's Mental Health Indicators: Summary of All Sources

\begin{tabular}{|c|c|c|c|c|c|c|c|c|}
\hline \multirow[t]{3}{*}{ Stage } & \multicolumn{7}{|c|}{ Population health framework component } & \multirow[t]{3}{*}{ Total } \\
\hline & \multicolumn{2}{|c|}{ Determinants } & \multicolumn{2}{|c|}{ Status } & \multicolumn{3}{|c|}{ Interventions } & \\
\hline & Protective & Risk & Strengths & Difficulties & Universal & Targeted & Clinical & \\
\hline All ages & 1 & 11 & - & 9 & - & - & 14 & 35 \\
\hline Early childhood only & 2 & 8 & 7 & 4 & - & - & - & 21 \\
\hline Middle childhood only & 1 & - & 2 & 6 & - & - & 2 & 11 \\
\hline Adolescence only & 1 & 1 & 6 & 12 & - & - & 3 & 23 \\
\hline Total & 5 & 20 & 15 & 31 & - & - & 19 & 90 \\
\hline
\end{tabular}

While 90 sample indicators may seem far from parsimonious, Table 5 illustrates that there were still significant imbalances in coverage of the comprehensive population health framework for children's mental health. (Each indicator is counted only once in Table 5, to produce a tally of unique indicators for each framework component.) For developmental stages, early childhood and adolescence were better represented than middle childhood, largely because of surveys specifically focusing on early childhood (NLSCY, EDI) or adolescence (CCHS, AHS). For determinants, risk factors greatly outweighed protective factors. Even so, there were few indicators for established risk factors such as child maltreatment. Similarly for status, difficulties greatly outweighed strengths, yet still it was not possible to derive robust indicators of the population prevalence and impact of disorders. The BCFPI did capture robust information on symptoms and impairment, but only for those children referred to selected community mental health agencies. Then regarding interventions, multiple indicators could be derived for clinical treatment and other downstream interventions, but indicators reflecting upstream interventions - promotion and prevention programs - were not available from any source. This is concerning because a system of indicators that captures only those children receiving services for established problems cannot provide policy-makers with reliable information on all children in the population, or information on those children not receiving services.

From a population health perspective, it was also striking that indicators of social determinants such as family socio-economic status and neighbourhood cohesion relied almost solely on data from two large Statistics Canada surveys, the Census and NLSCY. However, the detailed form of the Census was recently made voluntary and the Survey of Young Canadians recently replaced the NLSCY (although data from this new survey are not yet available). Both changes may exacerbate the imbalances in framework coverage, rendering it even more difficult to develop a truly comprehensive system of children's mental health indicators. 


\section{DISCUSSION}

Canada urgently requires a population health approach to children's mental health — promoting health and preventing disorders, in addition to providing treatment. Underpinning this approach, indicators could enable population monitoring, thereby informing ongoing public investments. To investigate potential indicators for British Columbia, we developed a comprehensive population health framework, established selection guidelines, reviewed data sources, and identified sample indicators. While 15 survey and administrative sources yielded 90 indicators, we nevertheless found a patchwork, with significant imbalances in coverage of the comprehensive population health framework.

Survey sources supplied considerable good-quality data, but the most comprehensive of these were undergoing significant changes, while the rest focused on selected segments of the child population. Meanwhile, administrative sources typically covered service populations only, with concurrent concerns about data quality or access (or both) in many cases. No one source permitted the derivation of the full array of indicators needed for population monitoring in children's mental health. Corroboration across sources was also seldom possible. Therefore, losing access to even a few sources could leave the patchwork looking threadbare. Finally, sample indicators were heavily weighted towards risks, difficulties, and "downstream" clinical interventions - likely reflecting the preponderance of current public investments, which have yet to appreciably improve children's mental health outcomes in the population.

We found that while it was feasible to derive children's mental health indicators from existing public data, it was not possible to develop a comprehensive system of indicators for B.C. To remedy this situation, three complementary options need to be considered: collecting new data, enhancing existing data sources, and evaluating existing programs.

The first option involves collecting new epidemiologic data on children's mental health. A rigorous and repeated cross-sectional survey in a representative sample in the population would be the ideal way to track children's social and emotional well-being over time. A well-designed survey could cover all components of the comprehensive population health framework, including uptake of effective promotion and prevention programs as well as access to effective treatment services. Launching and maintaining such a survey would be costly. However, the data could be made available through agencies such as Statistics Canada, enabling widespread use by researchers and policy-makers across the country. The costs of a new survey also need to be weighed against the opportunity costs of continuing with the status quo, in which children's mental disorders exact a high toll.

Another promising option involves enhancing existing high-quality data sources. The EDI and the BCFPI provide two notable examples, with researchers actively working to enhance both measures and expand their reach (Boyle et al., 2009; Janus \& Offord, 2007). In particular, the EDI is rapidly approaching Canada-wide coverage, with full implementation in most provinces/territories and partial implementation in the rest (Offord Centre for Child Studies, 2010). The latest version of the EDI includes new questions on diagnosed mental disorders in early childhood, which could be used in future waves of B.C. data collection (Human Early Learning Partnership, 2011). The newly created Middle Years Development Instrument will also soon be used to gather B.C. data on social and emotional well-being in middle childhood, following the EDI model (Guhn et al., in press). Meanwhile, the BCFPI has been implemented only in complex 
service settings in B.C. and Ontario to date, but it has considerable untapped population-wide potential for tracking symptoms and impairment associated with childhood mental disorders (Boyle et al., 2009). Taken together, the EDI and the BCFPI could also capture data across two important continua: early childhood through adolescence, and well-being through disorder. Building on the momentum of these two measures could arguably be the first step in creating a comprehensive system of children's mental health indicators.

Finally, evaluating existing promotion and prevention programs could be a means of patching the one major gap in available indicators. Numerous ECD programs across Canada currently employ both universal and targeted strategies to promote healthy child development. However, few of these programs have a clear focus on children's mental health, and even fewer have been rigorously evaluated (Waddell, McEwan et al., 2007). Ideally, ECD program outcomes would be evaluated from the outset, following the positive example of Ontario's Better Beginnings, Better Futures (Peters et al., 2010). Evaluations of the rare prevention programs that exist, such as B.C.'s Friends program, would be invaluable as well (Waddell, McEwan et al., 2007). Researchers would need to make evaluation data widely available to enable indicator development. However, clearly tracking the benefits for children, or clearly demonstrating insufficient programming, could help increase public support for new investments in promotion and prevention.

Ongoing population monitoring is a crucial means of tracking our collective progress towards improving the lives of all children. At present, it does not appear feasible to develop a truly comprehensive system of indicators for monitoring children's mental health in B.C. using existing public data. However, it appears possible to remedy this situation by collecting new epidemiologic data, enhancing existing high-quality data sources, and evaluating existing promotion and prevention programs. The potential benefits of undertaking these three options are immense, given that children's mental health is one of the most important investments that any society can make.

\section{REFERENCES}

Ben-Arieh, A. (2008a). The child indicators movement: Past, present, and future. Child Indicators Research, 1(1), 3-16.

Ben-Arieh, A. (2008b). Indicators and indices of children's well-being: Towards a more policy-oriented perspective. European Journal of Education, 43(1), 37-50.

Black, C., McGrail, K., Fooks, C., Baranek, P., \& Maslove, L. (2005). Data, data, everywhere: Improving access to population health and health services research data in Canada. Vancouver: University of British Columbia, Centre for Health Services and Policy Research.

Boyle, M.H., Cunningham, C.E., Georgiades, K., Cullen, J., Racine, Y., \& Pettingill, P. (2009). The Brief Child and Family Phone Interview (BCFPI): 2. Usefulness in screening for child and adolescent psychopathology. Journal of Child Psychology and Psychiatry, 50(4), 424-431.

Boyle, M.H., \& Georgiades, K. (2010). Perspectives on child psychiatric disorder in Canada. In J. Cairney \& D.L. Streiner (Eds.), Mental disorder in Canada: An epidemiological perspective (pp. 205-226). Toronto, ON: University of Toronto Press.

Boyle, M.H., \& Lipman, E.L. (2002). Do places matter? Socioeconomic disadvantage and behavioral problems of children in Canada. Journal of Consulting and Clinical Psychology, 70(2), 378-389.

Boyle, M.H., Offord, D.R., Hofmann, H.G., Catlin, G.P., Byles, J. A., Cadman, D.T., .. Szatmari, P. (1987). Ontario Child Health Study: I. Methodology. Archives of General Psychiatry, 44(9), 826-831.

Breton, J.J., Bergeron, L., Valla, J.P., Berthiaume, C., Gaudet, N., Lambert, J., ... Lepine, S. (1999). Quebec child mental health survey: Prevalence of DSM-III-R mental health disorders. Journal of Child Psychology and Psychiatry, 40(3), 375-384. 
Brownell, M., De Coster, C., Penfold, R., Derksen, S., Au, W., Schultz, J., \& Dahl, M. (2008). Manitoba child health atlas update. Winnipeg: Manitoba Centre for Health Policy.

Canadian Institute for Health Information. (2010). Health indicators 2010. Ottawa, ON: Author.

Cunningham, C.E., Boyle, M.H., Hong, S., Pettingill, P., \& Bohaychuk, D. (2009). The Brief Child and Family Phone Interview (BCFPI): 1. Rationale, development, and description of a computerized children's mental health intake and outcome assessment tool. Journal of Child Psychology and Psychiatry, 50(4), 416-423.

Earls, F., \& Carlson, M. (2001). The social ecology of child health and well-being. Annual Review of Public Health, $22,143-166$.

Essex, M.J., Kraemer, H.C., Armstrong, J.M., Boyce, W.T., Goldsmith, H.H., Klein, M.H., ... Kupfer, D. J. (2006). Exploring risk factors for the emergence of children's mental health problems. Archives of General Psychiatry, 63(11), 1246-1256.

Fergusson, D.M., Horwood, L.J., \& Ridder, E.M. (2005). Show me the child at seven: The consequences of conduct problems in childhood for psychosocial functioning in adulthood. Journal of Child Psychology and Psychiatry, 46(8), 837-849.

Government of Canada. (2007). The well-being of Canada's young children: Government of Canada report 2006. Ottawa, ON: Author.

Guhn, M., Schonert-Reichl, K.A., Gadermann, A.M., Marriott, D., Pedrini, L., Hymel, S., \& Hertzman, C. (in press). Well-being in middle childhood: An assets-based population-level research-to-action project. Child Indicators Research. doi: 10.1007/s12187-012-9136-8.

Hertzman, C., \& Williams, R. (2009). Making early childhood count. Canadian Medical Association Journal, 180(1), 68-71.

Human Early Learning Partnership. (2011, September 22). EDI data tables. Retrieved from http://earlylearning.ubc. $\mathrm{ca} / \mathrm{maps} / \mathrm{edi} / \mathrm{data} /$

Janus, M., Brinkman, S., Duku, E., Hertzman, C., Santos, R., Sayers, M., ... Walsh, C. (2007). The Early Development Instrument: A handbook on development, properties, and use. Hamilton, ON: McMaster University, Offord Centre for Child Studies.

Janus, M., \& Offord, D.R. (2007). Development and psychometric properties of the early development instrument (EDI): A measure of children's school readiness. Canadian Journal of Behavioural Science, 39(1), 1-22.

Jenkins, R. (1990). Towards a system of outcome indicators for mental health care. British Journal of Psychiatry, 157, 500-514.

Jenkins, R., Meltzer, H., Bebbington, P., Brugha, T., Farrell, M., McManus, S., \& Singleton, N. (2009). The British Mental Health Survey Programme: Achievements and latest findings. Social Psychiatry and Psychiatric Epidemiology, 44(11), 899-904.

Jokela, M., Ferrie, J., \& Kivimaki, M. (2009). Childhood problem behaviors and death by midlife: The British National Child Development Study. Journal of the American Academy of Child and Adolescent Psychiatry, 48(1), 19-24.

Junek, W. (2012). Government monitoring of the mental health of children in Canada: Five surveys (Part I). Journal of the Canadian Academy of Child and Adolescent Psychiatry, 21(1), 30-36.

Kershaw, P., Anderson, L., Warburton, B., \& Hertzman, C. (2009). 15 by 15: A comprehensive policy framework for early human capital investment in BC. Vancouver, BC: Human Early Learning Partnership.

Lim, K.L., Jacobs, P., Ohinmaa, A., Schopflocher, D., \& Dewa, C.S. (2008). A new population-based measure of the economic burden of mental illness in Canada. Chronic Diseases in Canada, 28(3), 92-98.

Moore, K.A., \& Theokas, C. (2008). Conceptualizing a monitoring system for indicators in middle childhood. Child Indicators Research, 1(2), 109-128.

Moore, K.A., Vandivere, S., Atienza, A., \& Thiot, T. (2008). Developing a monitoring system for indicators in middle childhood: Identifying measures. Child Indicators Research, 1, 129-155.

Mrazek, P., Biglan, A., \& Hawkins, J.D. (2004). Community-monitoring systems: Tracking and improving the well-being of America's children and adolescents. Falls Church, VA: Society for Prevention Research.

Mrazek, P.J., \& Haggerty, R.J. (Eds.). (1994). Reducing risks for mental disorders: Frontiers for preventive intervention research. Washington, DC: National Academy Press.

Offord Centre for Child Studies. (2010, June 15). EDI coverage across Canada: 1999 to 2010. Retrieved from http:// www.offordcentre.com/readiness/files/2010_Implementation_in_Canada_Map.pdf 
Offord, D.R., Boyle, M.H., Szatmari, P., Rae-Grant, N. I., Links, P.S., Cadman, D.T., ... Byrne, C. (1987). Ontario Child Health Study: II. Six-month prevalence of disorder and rates of service utilization. Archives of General Psychiatry, 44(9), 832-836.

Offord, D.R., Kraemer, H.C., Kazdin, A.E., Jensen, P.S., \& Harrington, R. (1998). Lowering the burden of suffering from child psychiatric disorder: Trade-offs among clinical, targeted, and universal interventions. Journal of the American Academy of Child and Adolescent Psychiatry, 37(7), 686-694.

Peters, R.DeV., Bradshaw, A.J., Petrunka, K., Nelson, G., Herry, Y., Craig, W.M., . . Rossiter, M.D. (2010). The Better Beginnings, Better Futures project: Findings from Grade 3 to Grade 9. Monographs of the Society for Research in Child Development, 75(3), 1-174.

Pollard, E.L., \& Lee, P.D. (2003). Child well-being: A systematic review of the literature. Social Indicators Research, $61(1), 59-78$.

Rutter, M. (2006). Implications of resilience concepts for scientific understanding. Annals of the New York Academy of Sciences, 1094, 1-12.

Rutter, M. (2009). Understanding and testing risk mechanisms for mental disorders. Journal of Child Psychology and Psychiatry, 50(1), 44-52.

Shanahan, L., Copeland, W., Costello, E.J., \& Angold, A. (2008). Specificity of putative psychosocial risk factors for psychiatric disorders in children and adolescents. Journal of Child Psychology and Psychiatry, 49(1), 34-42.

Waddell, C., McEwan, K., Peters, R., Hua, J.M., \& Garland, O. (2007). Preventing mental disorders in children: A public health priority. Canadian Journal of Public Health, 98(3), 174-178.

Waddell, C., McEwan, K., Shepherd, C.A., Offord, D.R., \& Hua, J.M. (2005). A public health strategy to improve the mental health of Canadian children. Canadian Journal of Psychiatry, 50(4), 226-233.

Waddell, C., Offord, D.R., Shepherd, C.A., Hua, J.M., \& McEwan, K. (2002). Child psychiatric epidemiology and Canadian public policy-making: The state of the science and the art of the possible. Canadian Journal of Psychiatry, 47(9), 825-832.

Waddell, C., Shepherd, C.A., \& Barker, J. (2007). Developing a research-policy partnership to improve children's mental health in British Columbia. Canadian Western Geographical Series, 41, 183-198.

Waddell, C., Shepherd, C.A., \& McLauchlin, G. (2008). Creating mentally healthy communities, starting with children. In Canadian Population Health Initiative (Ed.), Mentally healthy communities: A collection of papers (pp. 45-58). Ottawa, ON: Canadian Institute for Health Information.

Willms, J.D. (Ed.). (2002). Vulnerable children: Findings from Canada's National Longitudinal Study of Children and Youth. Edmonton: University of Alberta Press.

Winters, N.C., Collett, B.R., \& Myers, K.M. (2005). Ten-year review of rating scales, VII: Scales assessing functional impairment. Journal of the American Academy of Child and Adolescent Psychiatry, 44(4), 309-338. 